\title{
An evaluation of gender bias and pupils' attitude towards STEM disciplines in the transition between compulsory and voluntary schooling
}

\author{
Alessandro Siani* and Claudiu Dacin \\ School of Biological Sciences, University of Portsmouth, Portsmouth, UK \\ ${ }^{*}$ Corresponding Author: alessandro.siani@port.ac.uk
}

Keywords: STEM; Pipeline; Gender bias; Women in STEM; Science education; Skills shortage; Key Stage 4; Key Stage 5.

\begin{abstract}
Tackling the Science, Technology, Engineering, and Mathematics (STEM) skills shortage is an ongoing challenge for governments and policymakers worldwide. While the last decade has seen an increase in student enrolment into STEM degree courses in the UK, the gender gap remains a persistent issue in academia. In order to understand the causes underpinning female under-representation in STEM, it is essential to consider the whole academic pipeline and identify its "leaky points". As the transition between compulsory and voluntary schooling represents a critical attrition point in the STEM educational pipeline, we conducted a survey to investigate the attitude of a cohort of year 11 and year 12 pupils towards STEM disciplines. Our results indicate that a gender bias is already evident at General Certificate of Secondary Education (GCSE) level, where only $25 \%$ of girls expressed the intention to pursue a career in STEM. In both age groups, girls expressed a considerably lower preference for chemistry, physics and ICT, and a higher preference for biology compared to boys in the same year group. Participation in extracurricular activities and parents' educational status both showed a strong correlation with pupils' intention to undertake STEM studies in higher education and pursue a career in a related field. A recurring theme emerging from the survey is that pupils are
\end{abstract}

eager to gain more knowledge about "real life" applications of science and are inspired by interactions with visiting scientists. These results corroborate the notion that outreach activities have a crucial role in promoting engagement in STEM subjects amongst young learners, and are essential towards the endeavour of "mending the pipeline" at an early stage.

\section{Introduction}

\section{Background}

Addressing the gender gap in STEM (Science, Technology, Engineering, and Mathematics) subjects is a major challenge across workplaces and educational institutions worldwide. According to a 2017 publication from the UNESCO Institute for Statistics, women represent on average less than $30 \%$ of total researchers, with representation as low as $19 \%$ in South and West Asia (Fact Sheet No. 43: Women in Science, 2017). As concisely described in a recent National Audit Office (NAO) report, in the UK "Females are under-represented in most STEM subject areas at every stage of the STEM skills pipeline" (Delivering STEM (science, technology, engineering and mathematics) skills for the economy, 2018). The progressive loss of female workforce along the STEM academic and professional pipeline has been extensively characterised, 
and several of its causes identified by previous studies. It is no surprise that multiple concurring factors underpin the "pipeline leakage", and indeed the relative impact of each factor varies widely between countries, institutions, discipline, career stage, etc. (Kahn \& Ginther, 2017). The gender gap is particularly pronounced in certain STEM disciplines, particularly engineering, physics, and (to a lesser extent) chemistry (The Supply of and Demand for High-Level STEM Skills, 2013). The prevalence of this trend has been widely reported at all stages of the academic pipeline, and can be traced all the way back to compulsory education (Cheryan, Ziegler, Jiang, \& Montoya, 2017).

The present paper is broadly divided into two main parts: in the first part we will give a snapshot of the main stages of the STEM professional and educational pipeline, walking our way backwards from the workplace, through higher education, to school classrooms, in an effort to describe the extent and causes of the "leaks" at each stage and set the scene for the following section.

In the second part we will discuss the results of a study we carried out in West Sussex (UK) to investigate the perspective of a cohort of Key Stage 4 and Key Stage 5 pupils on STEM subjects and their relevance to our society. While the STEM gender gap has been extensively characterised and quantified at all levels of the UK academic pipeline by scholars and government agencies alike, there is a relative shortage of studies evaluating the perspectives of the most directly interested party (i.e. the students themselves) to pinpoint the factors that might cause or aggravate the gap. Hence, the aim of the present investigation is to elucidate the factors that might drive school-age pupils towards (or away from) a career in STEM and to assess whether gender plays a role in their choice.

Our study specifically focuses on the factor(s) contributing to the loss of potential future STEM workforce in what we believe is a crucial moment in students' academic (and broader) life: the transition between compulsory and voluntary schooling. For readers interested in a more detailed analysis of other stages of the STEM academic pipeline, a wealth of further information is available from organisations such as, among others, UNESCO (www.unesco.org), Equality Challenge Unit (www.ecu.ac.uk), and WISE (www.wisecampaign.org.uk).

\section{Skills shortage and gender gap in the STEM workforce}

As clearly stated in the latest UK government Industrial Strategy white paper, "The number of STEM undergraduates has been increasing over the last few years, but there remains unmet demand from employers. 40 per cent of employers reported a shortage of STEM graduates as being a key barrier in recruiting appropriate staff" (Industrial Strategy: Building a Britain fit for the future, 2017). While the extent of the issue has proven hard to quantify, with widely different figures brought forward by different sources, the STEM shortage has been estimated (based on data from 2015) at 790,221 missing employees for graduate jobs, 318,078 for postgraduate, and 716,027 for experienced (5+ years) positions (Delivering STEM (science, technology, engineering and mathematics) skills for the economy, 2018).

STEM jobs constitute a significant proportion of the entries in the "United Kingdom Shortage Occupation List" recently published by the Home Office, who are trying to facilitate the attraction and retention of foreign skilled workers under a Tier 2 Visa (Immigration Rules, 2016, last updated on 6/4/2018). While the intake of foreign skilled workers has greatly mitigated the extent of the STEM recruitment shortage over the last decades (Immigration: Keeping the UK at the heart of global science and engineering, 2016), female under-representation continues to be a key factor in the persistence of the shortfall of specialised skills (Delivering STEM skills for the economy, 2018; Industrial Strategy: Building a Britain fit for the future, 2017). It has been estimated that around half of STEM graduates end up working in non-STEM jobs (The Supply of and Demand for High-Level STEM Skills, 2013), with women reportedly constituting a mere $23 \%$ of the British STEM workforce (Women in STEM workforce, 2017). 
Several studies have sought to pinpoint the factors underpinning female underrepresentation in the STEM workforce. In addition to the progressive loss that takes place at all steps of the STEM educational pipeline (which we will discuss in more details in the following sections), a major "leaky point" seems to be the progression from entry-level graduate jobs to more advanced, higher paying positions (Kahn \& Ginther, 2017). While there is abundant literature on female under-representation in STEM subjects in the academic context, describing the extent of the phenomenon in the private sector has proven more challenging due to the inherent complexity of gathering detailed data from a widely diverse range of private companies. Data collected from 583 companies and 3.2 million employees from 42 countries indicate that women only constitute around $35 \%$ of the workforce at the professional level, and only $20 \%$ at the executive level (When women thrive, businesses thrive, 2016). While these figures indicate a widespread gender disparity across all professional sectors, workforce analysis in the private R\&D sector paints an even bleaker picture. According to a recent report, over half of biotech companies in the US and European market have all-male boards, with female representation being over the $25 \%$ mark in only $7 \%$ of the companies analysed (Investing in biotechnology management: Venture Capital and Hiring Insights on Gender, 2015). The same report indicates that "The funding of private biotechnology companies remains heavily oriented towards male CEOs and all-male boards", with women only representing $3 \%$ of CEO appointments in the sector, and only $1 \%$ of the total capital being invested in companies with at least $50 \%$ female board members. Similarly, despite women constituting $75 \%$ of employees in the UK National Health Service $(61 \%$ in the pharmaceutical sector), they only constitute $47 \%$ (36\% in the pharmaceutical sector) of "very senior managers" (Analysis of the representation of women across the hospital and community health services workforce, 2018).

In a comprehensive 2014 monograph, Ceci and colleagues sought to map the professional trajectory of men and women in academic positions in STEM and non-STEM subjects (Ceci, Williams, Ginther, \& Kahn, 2014). While representation of women along all stages of the academic pipeline has significantly increased over the analysed period (1973-2010) in most subject areas, the gender gap is far from having being filled: the percentage of Bachelor's degrees awarded to women in 2010 was below $50 \%$ in all core STEM subjects (with the exception of Life Sciences), with figures dropping below the $20 \%$ mark in tenured and tenure-track positions. Similar results were reported in a more recent study, where the retention and promotion of under-represented minorities was described in STEM faculties across four large land grant institutions (Gumpertz, Durodoye, Griffith, \& Wilson, 2017). As in the previously mentioned monograph, while the gender gap seems to have generally narrowed down over time (1992-2015), the percentage of female appointments as tenure track assistant professor is still around or below the $30 \%$ mark in all four institutions.

In 2005, the Equality Challenge Unit (ECU) established the Athena SWAN charter "to encourage and recognise commitment to advancing the careers of women in science, technology, engineering, maths and medicine (STEMM) employment in higher education and research" ("Athena SWAN Charter Equality Challenge Unit," 2018). Since then, 96 universities, 587 departments, and 16 research institutes have seen their commitment to the Athena SWAN charter recognised, with a total of 699 awards having been granted as of October 2017. An independent report carried out at Loughborough University indicated that a positive culture change was observed in institutions and departments adhering to the Athena SWAN charter, and "there was considerable evidence [...] that career satisfaction, opportunities for training and development, knowledge of promotion processes and fairness in the allocation of workload" had improved in a sustainable fashion as a result (Munir et al., 2013). Interestingly, the report also indicated that "the Athena SWAN award process did not yet seem to have impacted upon undergraduate students based on the lack of differences in responses across Athena SWAN and no 
award categories to nearly all questions on the undergraduate survey", and that "There was evidence of a lack of awareness among postgraduates of university and department policies relating to Athena SWAN".

\section{Overview of the STEM educational pipeline} In 2011, three years before the Loughborough University report was released, Emma Smith had already come to comparable conclusions, highlighting how "almost three decades of initiatives to increase participation in STEM subjects have had little noticeable impact on the recruitment data and gendered patterns of participation persist in several subject areas" (Smith, 2011). Smith's data indicate that, while the overall average gender ratio for $\mathrm{HE}$ recruitment in science subjects reached near parity in the UK by 2004, individual subjects still show widely different figures. For examples, while females represented around $55 \%$ of undergraduate students in medical and biological sciences in 2009, the figures drop below $40 \%$ for physical sciences, and around $10 \%$ for engineering sciences.

More recent data from the UK Higher Education Statistics Agency (HESA) support the observation of a profoundly split STEM landscape, with women having the majority share in medical and biological sciences $70 \%$ of undergraduate qualifications), while being heavily under-represented in physical and mathematical sciences $(40 \%$ and $39 \%$, respectively) and, most significantly, computer sciences (16\%) and engineering/technology (14\%) (Higher education student enrolments and qualifications obtained at higher education providers in the United Kingdom 2015/16, 2018). Interestingly, statistics published by the WISE campaign indicated that "In most postgraduate subjects, gender segregation decreases when compared to undergraduate subjects" (Botcherby \& Buckner, 2012). It is however worth pointing out that, even in the fields in which they are more represented, female doctoral students' publication rates are significantly lower than those of their male counterparts (Lubienski, Miller, \& Saclarides, 2017). It is reasonable to think that the differential research output during early career stages might be a key factor contributing to the STEM workplace gender disparity discussed in the previous section.

In a study recently published in the British Educational Research Journal, Natasha Codiroli sought to investigate the impact of students' backgrounds on their engagement with STEM subjects at level 3 and 4 (Codiroli, 2017). The author analysed by logistic regression the combined impact of key variables (gender, ethnicity, socio-economic position) on subject choice in a population of over 4000 English students. Interestingly, the results suggest that "young women from more advantaged backgrounds are more likely to choose STEM subjects, whilst those from relatively deprived backgrounds are more likely to study SLB (Social Sciences, Law and Business) subjects". Codiroli proposes that risk aversion theory can be applied to elucidate these findings, suggesting that women from a disadvantaged background might be less likely to take a choice (STEM career) perceived as "risky", and veer towards "safer" careers with similar financial returns such as Social Sciences, Law and Business \& administrative.

In addition to socio-economic position, several other factors have been identified as potential causes of female attrition in the early stages of the STEM educational pipeline. Attrition factors such as (among others) unconscious bias, lack of positive reinforcement, and unsuitable teaching approaches can be directly related to the scholastic environment (Boaler, 2002; Campbell, 2015; Mujtaba \& Reiss, 2012). An analysis of a cohort of 4985 pupils from English state (i.e. government funded) schools indicates that gender stereotyping and unconscious bias can be identified as early as in year two, where girls' performance in maths is systematically underassessed (Campbell, 2015). Moreover, it has been observed that even amongst high achievers $\left(A^{*}\right.$ in mathematics or physics at GCSE level) girls are less likely to choose to pursue an Advanced level (henceforth A-level) in those subjects than their male counterparts, with $64 \%$ of girls ( $80 \%$ of boys) taking up mathematics, and only $13 \%$ of girls $(64 \%$ of boys) taking up physics at A-levels (Boaler, Altendorff, \& Kent, 2011). It is worth pointing out that educational institutions might have a 
negative impact on girls' retention in STEM not only due to unconscious bias and lack of positive reinforcement, but also by using inadequate teaching strategies. Jo Boaler carried out a longitudinal study following approximately 300 students from age 13 to 16 in two British schools (Boaler, 2002). While one of the schools had a traditional (teacherfocused) approach to maths teaching, the other a focus on problem-solving and enquirybased learning. The outcomes of the study indicated that girls achieved lower than males in the traditional approach, while both genders showed equal achievement with the problemsolving approach. According to the author, "Both sets of students expressed preferences for open, discussion-oriented work, but boys adapted to the converse of this, whereas the girls generally did not. The boys tended to rush through questions to achieve speed, if not understanding. The girls would not do this; they seemed unable to suppress their desire for understanding and continued to strive toward it, which probably worked to their disadvantage". Unsurprisingly, Boaler's study also showed that girls felt frustrated by their difficulty in understanding the topics being taught and their low attainment, ultimately resulting in widespread disaffection towards the subject.

Attribution theory has been used to link the underachievement (be it effective or perceived) of females with their detachment from and loss of engagement with STEM subjects. With reference to Weiner's taxonomy of attributions, school-age girls have been shown to be more likely than boys to attribute the causes of failure to internal factors (e.g. their own lack of ability) while providing external attributions (e.g. subject ease) for success (Nelson \& Cooper, 1997; Ryckman \& Peckham, 1987). Similarly, LaCosse and colleagues reported that attribution bias is a key factor in female attrition in higher education, concluding that "When women perceive that women are undervalued, belittled, or ignored in STEM settings, this can affect their spontaneous attributional responses in a way that promotes and maintains gender-STEM stereotypes, and ultimately lowers women's intentions to remain in STEM fields or pursue STEM careers" (LaCosse, Sekaquaptewa, \&
Bennett, 2016). It can therefore reasonably be argued that attrition along the STEM educational pipeline could be attributed to complex combination of external (e.g. lack of positive reinforcement) and internal (maladaptive attribution patterns) factors, that ultimately contribute to a state akin to learned helplessness in female students (Dweck, 1986; Dweck, Davidson, Nelson, \& Enna, 1978; Qian \& Alvermann, 1995).

While in this section we have mainly focused on the educational landscape in the UK; readers interested in a comprehensive evaluation of the status of women in STEM in US schools and universities might wish to refer to recent articles by, respectively, Sadler (2012) and Blackburn (2017).

\section{Study design}

With the present study we sought to investigate the outlook of a cohort of Key Stage 4 and Key Stage 5 pupils on STEM subjects, and whether their perspectives differ by gender and year group. A survey was carried out in a high school (year 7 to year 11) and a college (year 12 to year 13) located in West Sussex (UK). The two institutions (names are intentionally omitted) were selected for convenience reasons due to their geographical proximity and academic links between the authors of the study and the school's and college's teaching staff.

Both institutions were, at the time the survey was conducted, following the AQA curriculum specifications (AQA Science Curriculum, 2018). For the survey, questionnaires were provided as hard copies and distributed by form tutors in the high school, and by science teachers in the college to pupils studying at least one science subject towards their GCSEs or A-levels, respectively. Year 11 pupils were taking either "Combined Science Trilogy", which leads to the award of two science GCSEs, or (optionally) triple science, leading to the award of a GCSE in each of the separate sciences. Year 12 pupils were studying at least one of the three sciences (Physics, Chemistry, Biology) towards their Alevels, with several participants studying a combination of more than one science subjects or mathematics. A total of 140 pupils (70 in each institution) participated in the 
survey by completing and returning the questionnaire. The year 11 group was composed of 28 males and 37 females, with 5 pupils choosing the "prefer not to say" option. The year 12 group showed a more even gender distribution, with 36 males and 34 females participating in the survey.

It is important to highlight that, while for the high school group the study of (at least) core science GCSE was compulsory, the year 12 pupils had chosen to pursue their science Alevels, meaning that the Key Stage 5 cohort was composed of students who had already committed to, or shown a preference for, the study of science subjects. The survey contained eight multiple-choice questions designed to identify and quantify any trends between students' backgrounds and their outlook towards (and engagement with) STEM subjects; the multiple-choice questions were followed by an open question designed to gather qualitative data to corroborate the numerical findings and gain further insight in the pupils' perspectives.

- What gender were you assigned at birth?

- Does one or more of your parents/guardians have a University degree?

- Which subjects do you enjoy the most from the list below?

- What are you planning to do after finishing your GCSEs/A-levels?

- Does your school offer any extracurricular Science, Technology, Engineering and Mathematics activities?

- If you answered "Yes" to the previous question, do you attend any of those activities?

- Are you thinking of pursuing a STEMrelated career?

- Where do you usually hear sciencerelated news from?

- How could we make science lessons more interesting and appealing to you?

Prior to the start of the investigation, consent to carry out the survey was obtained from the two participating institutions and ethical approval (reference number SFEC 2018-015) granted from the University of Portsmouth
Science Faculty Ethics Committee. Participation in the study was voluntary and anonymous; all pupils taking part in the survey were informed on the aim and modalities of the study, and on their right to withdraw from it.

\section{Results}

\section{Subject preference}

While the question "Which subjects do you enjoy the most?" might sound like a banal and trite one, it provides a clear depiction of the preferences of a group of students. The results shown in figure 1 confirm the observations of a radically split STEM landscape. In the year 11 group, boys expressed significantly higher preferences for maths, chemistry, physics, and ICT than girls did. On the other hand, nearly twice as many girls expressed a preference for biology than boys, a figure remarkably close to the gender ratio in undergraduate qualifications in medical and biological sciences ("Higher education student enrolments and qualifications obtained at higher education providers in the United Kingdom 2015/16 | HESA," 2018). In the Key Stage 4 cohort, males also seemed to show a higher number of preferences for physical education (PE), whereas females greatly outnumbered them in English, languages, business, and geography.

A similar trend could be observed in the year 12 cohort, with biology receiving an overwhelming share of preferences from girls, while a marked male preference could be observed for physics, chemistry, and ICT. Interestingly, while year 11 boys were over twice more likely $(32 \%)$ to express a preference for mathematics compared with girls $(13 \%)$ in the same year group, an opposite trend can be observed in the year 12 cohort, where $41 \%$ of girls and $28 \%$ of boys expressed a preference for mathematics.

While references to "technology" and "engineering" were included in the questionnaire for their inherent relevance to the topic of STEM education, it is worth stressing that the meanings attributed to those words by school-age students are not univocal, and in many cases not clear. Pupils' 

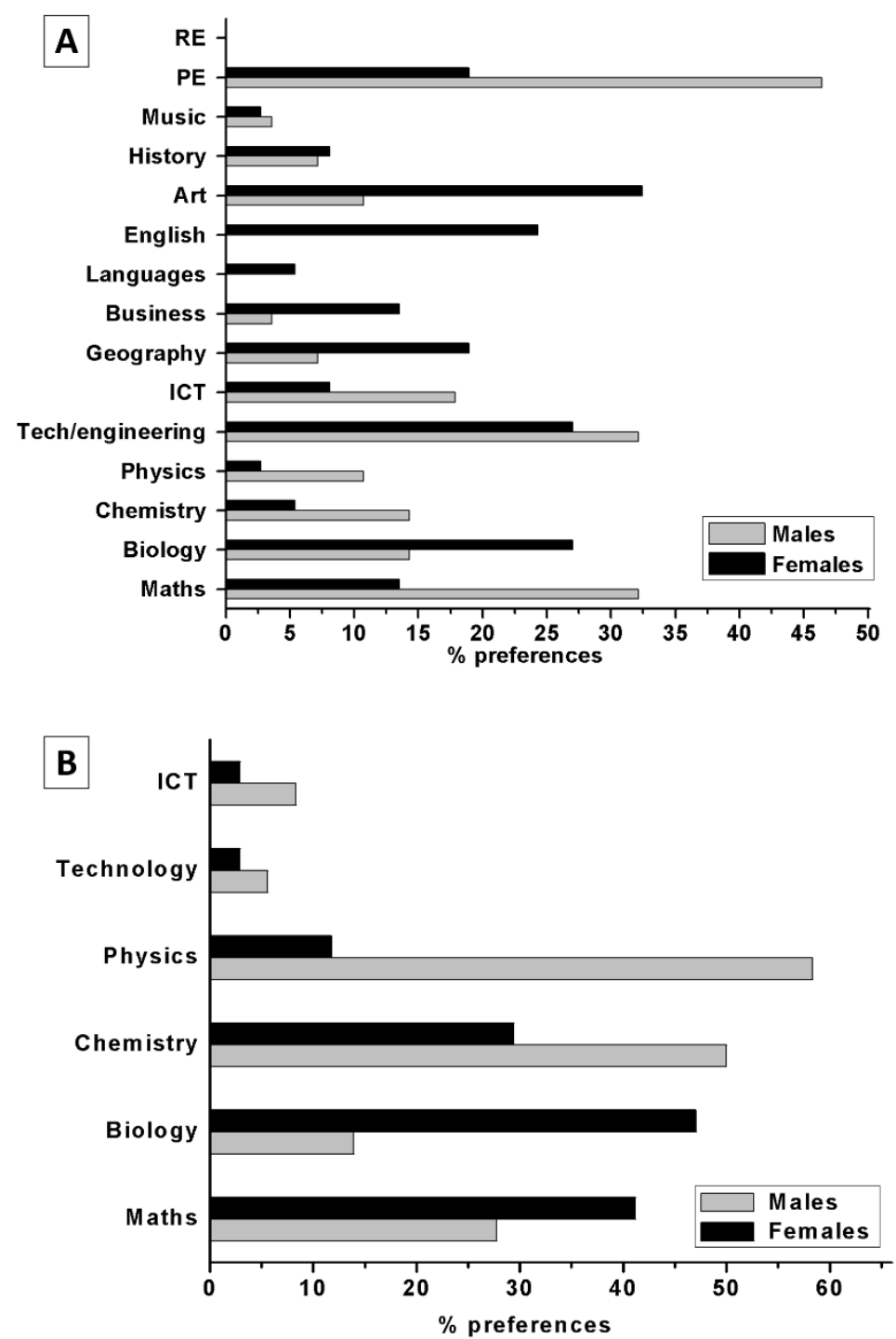

Figure 1 Pupils' subject preference in year $11(\mathrm{~A})$ and year $12(\mathrm{~B})$. The percentage was calculated for each individual subject as the percentage of pupils who expressed preference for that specific subject. As participants could express multiple preferences, the sum of all preferences is above $100 \%$.

answers to the open questions in the questionnaire indicated that different students attributed different meanings to the word "technology", with specific references to either "Food technology" or "Design and Technology". Similarly, as engineering is not explicitly included as a stand-alone subject in the Key Stage 4 and Key Stage 5 curricula, pupils showed widely mixed understanding of its nature and relevance. As a result of the arguably vague definition provided in the questionnaire, and of the participants' uncertainty on the nature of "technology" and "engineering", the results pertaining to those two subjects will not be further evaluated in this paper.

\section{Factors influencing educational choices}

The transition between compulsory and voluntary schooling (level 2 to level 3 ) and from secondary to higher education (level 3 to level 4) are critical in shaping students' academic careers. It is therefore of paramount importance to elucidate the factors influencing pupils' choices of educational paths.

Our results (Figure 2A) highlight a gender disparity in pupils' choices of post-16 education in the year 11 group, where $62 \%$ of 

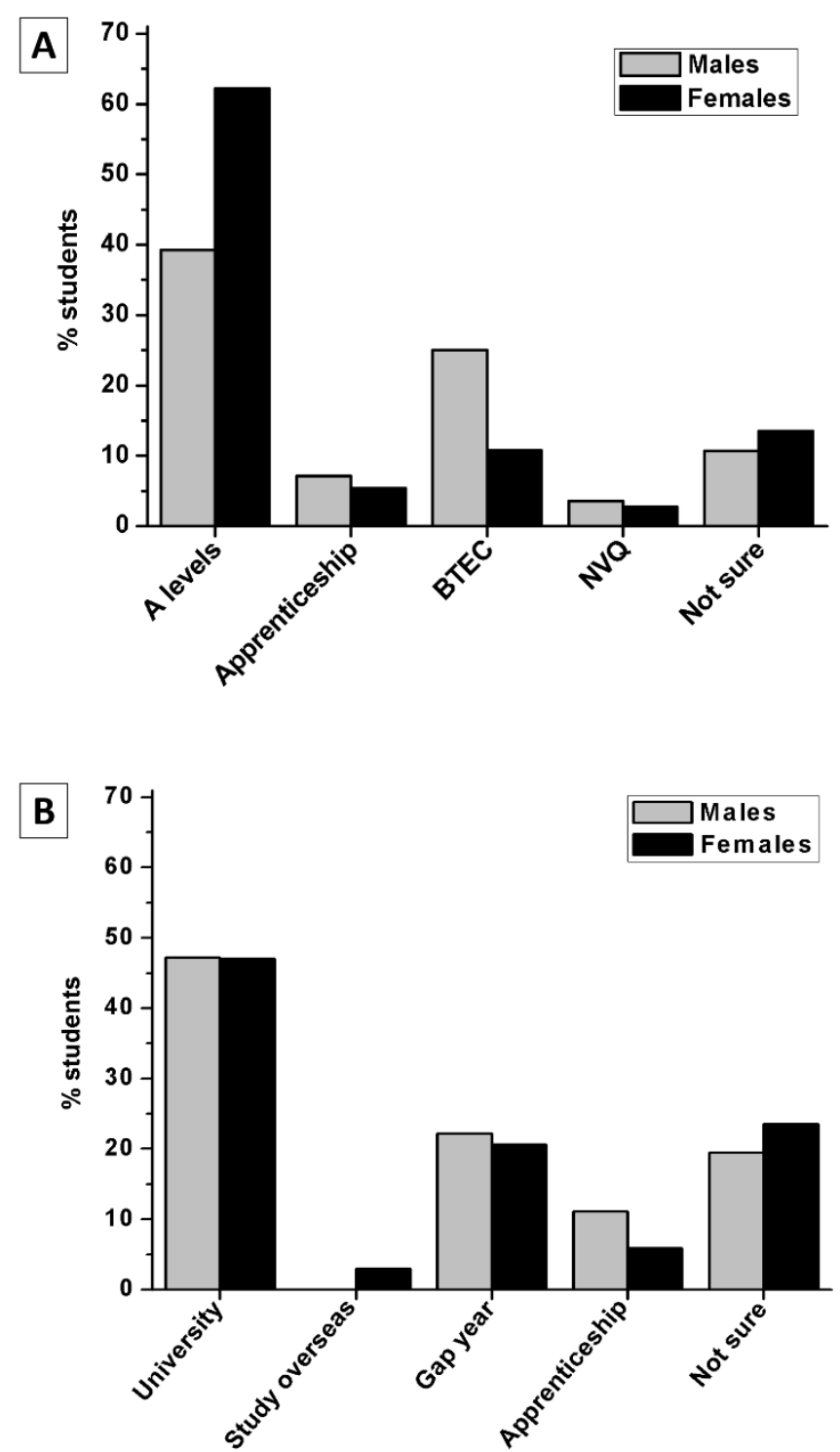

Figure 2 Pupils' educational plans after completing their GCSEs (A) and A levels (B). Each participant could express a single preference.

females expressed the intention to enrol into an A-level course compared to only $39 \%$ of males. On the other hand, males expressed a higher preference than females towards more applied educational choices, such as apprenticeships, National Vocational Qualification (NVQ) and most noticeably Business and Technology Education Council diploma (BTEC), which was chosen by $25 \%$ of boys and only $11 \%$ of girls. A much smaller gender imbalance could be observed in the year 12 group (Figure 2B), where a nearly identical share of males and females expressed the intention to pursue further studies at a university. In contrast, nearly twice as many year 12 boys planned to pursue an apprenticeship after completing their A-levels compared to girls in the same year group. In both year groups, females were marginally more likely than males to express uncertainty, responding that they are "not sure" of their plans after completing their current study cycle.

A striking gender imbalance was observed in Key Stage 4 pupils' answers to the question: "Are you thinking of pursuing a STEM-related career?". As can be seen in figure $3 \mathrm{~A}$, only $24 \%$ of year 11 girls gave a positive answer, as opposed to $50 \%$ of the boys. Conversely, our data show negligible gender imbalance ( $83 \%$ of males and $82 \%$ of females) in year 12 pupils' intentions to pursue a career in the STEM field. 

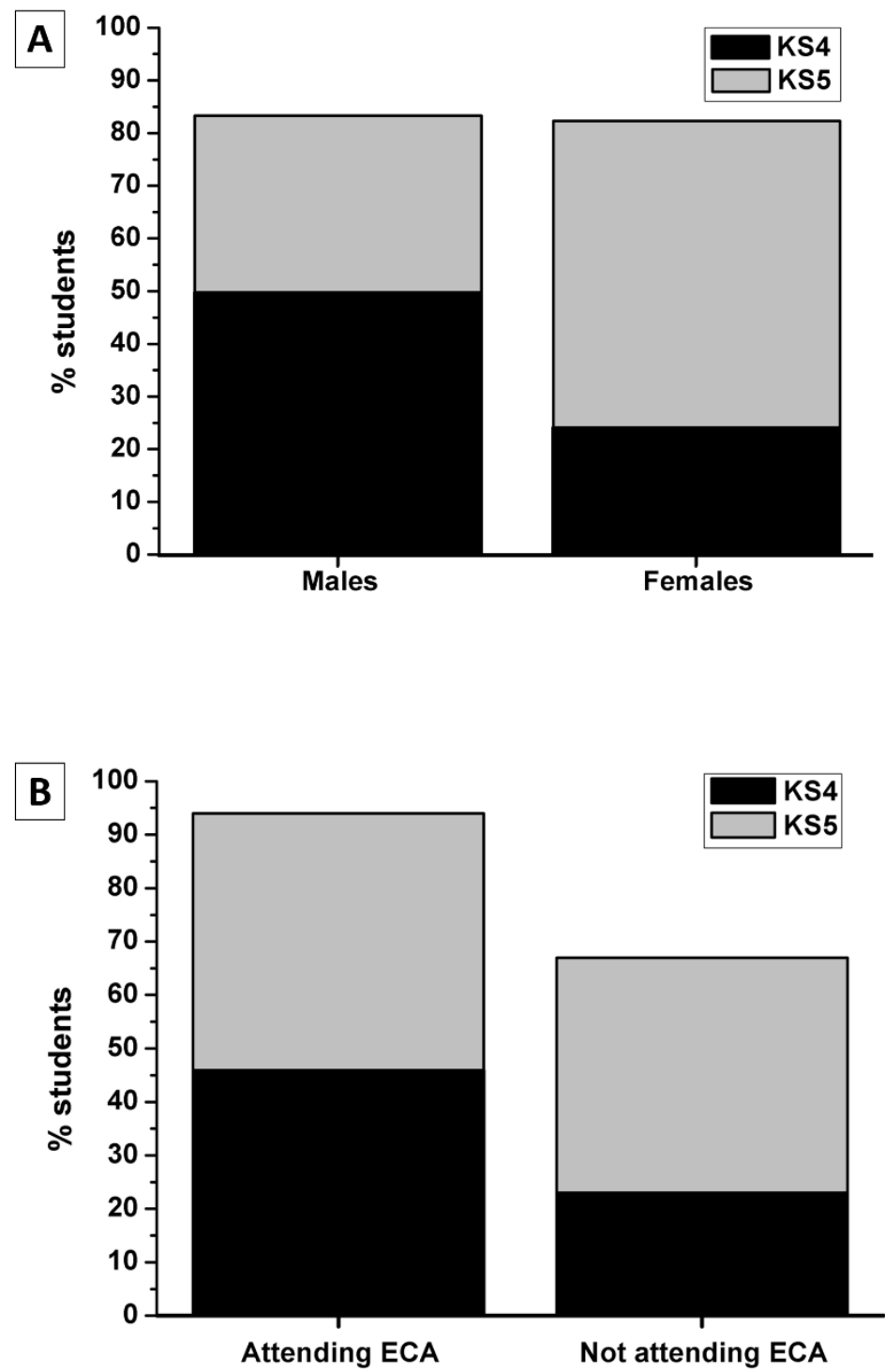

Figure 3 Percentage of year 11 (KS4) and year 12 (KS5) pupils expressing the intention to pursue a career in a STEM-related field, subdivided by gender (A) and attendance to extracurricular activities (B). The percentages are calculated in relation to the total participants of the same gender in the same age group (e.g. 50\% of year 11 boys expressed the intention to pursue a career in STEM, as opposed to $24 \%$ of year 11 girls). 


\begin{tabular}{|c|c|c|c|}
\hline \multirow{6}{*}{ A } & $\begin{array}{l}\text { Plan after completing } \\
\text { GCSEs }\end{array}$ & $\begin{array}{c}\text { Pupils with a least one } \\
\text { parent/carer in possession } \\
\text { of a university degree }\end{array}$ & $\begin{array}{c}\text { Pupils without a } \\
\text { parent/carer in possession } \\
\text { of a university degree }\end{array}$ \\
\hline & A levels & $77 \%$ & $42 \%$ \\
\hline & Apprenticeship & $9 \%$ & $4 \%$ \\
\hline & BTEC & $5 \%$ & $31 \%$ \\
\hline & $N V Q$ & $0 \%$ & $4 \%$ \\
\hline & Not sure & $9 \%$ & $19 \%$ \\
\hline \multirow{6}{*}{ B } & $\begin{array}{c}\text { Plan after completing A } \\
\text { levels }\end{array}$ & $\begin{array}{c}\text { Pupils with a least one } \\
\text { parent/carer in possession } \\
\text { of a university degree }\end{array}$ & $\begin{array}{c}\text { Pupils without a } \\
\text { parent/carer in possession } \\
\text { of a university degree }\end{array}$ \\
\hline & University & $53 \%$ & $44 \%$ \\
\hline & Study overseas & $0 \%$ & $4 \%$ \\
\hline & Gap year & $25 \%$ & $24 \%$ \\
\hline & Apprenticeship & $3 \%$ & $12 \%$ \\
\hline & Not sure & $19 \%$ & $16 \%$ \\
\hline \multirow{3}{*}{ C } & & $\begin{array}{l}\text { Pupils with a least one } \\
\text { parent/carer in possession } \\
\text { of a university degree }\end{array}$ & $\begin{array}{c}\text { Pupils without a } \\
\text { parent/carer in possession } \\
\text { of a university degree }\end{array}$ \\
\hline & $\begin{array}{l}\text { Year } 11 \text { pupils planning to } \\
\text { pursue a career in a STEM- } \\
\text { related subject }\end{array}$ & $50 \%$ & $25 \%$ \\
\hline & $\begin{array}{l}\text { Year } 12 \text { planning to pursue } \\
\text { a career in a STEM-related } \\
\text { subject }\end{array}$ & $89 \%$ & $76 \%$ \\
\hline
\end{tabular}

Table 1 Correlation between parents' education status and pupils' educational plans after completing their GCSEs (A) and A levels (B). Table $1 \mathrm{C}$ shows the correlation between parents' educational status and pupils' intentions of pursuing a career in the STEM field.

We also sought to investigate whether a correlation could be identified between pupils' academic choices and the education status of their parents or carers (Table 1). Similarly to what was described in the previous paragraphs, a larger divide could be observed within the year 11 group than within the year 12 group. Strikingly, year 11 pupils whose parents or carers are not in possession of a university degree are $35 \%$ less likely to consider studying towards A-levels, $26 \%$ more likely to enrol on a BTEC course, and $10 \%$ more likely to be undecided. A similar (albeit once again much less pronounced) trend can be observed in the year 12 cohort, where pupils whose parents/carers do not have a degree are $9 \%$ less likely to consider going to university and $9 \%$ more likely to choose an apprenticeship.

\section{Engagement with STEM extracurricular activities}

Extracurricular activities (ECA) have a welldocumented impact on students' attainment across all subjects and educational levels, and it has been widely reported that engagement with extracurricular experiences is a predictor of "strong talent and interest in STEM" (Bottia et al., 2015; VanMeter-Adams et al., 2014). It is therefore extremely important to investigate the engagement of pupils in extracurricular activities at a transition stage crucial towards their academic career. Worryingly, our results (Figure 4) indicate that in both year groups females were substantially less likely to engage in STEM extracurricular activities than males in the same year group. These results were particularly pronounced in the year 11 cohort (Figure $4 A$ ), where only $59 \%$ of girls (as 

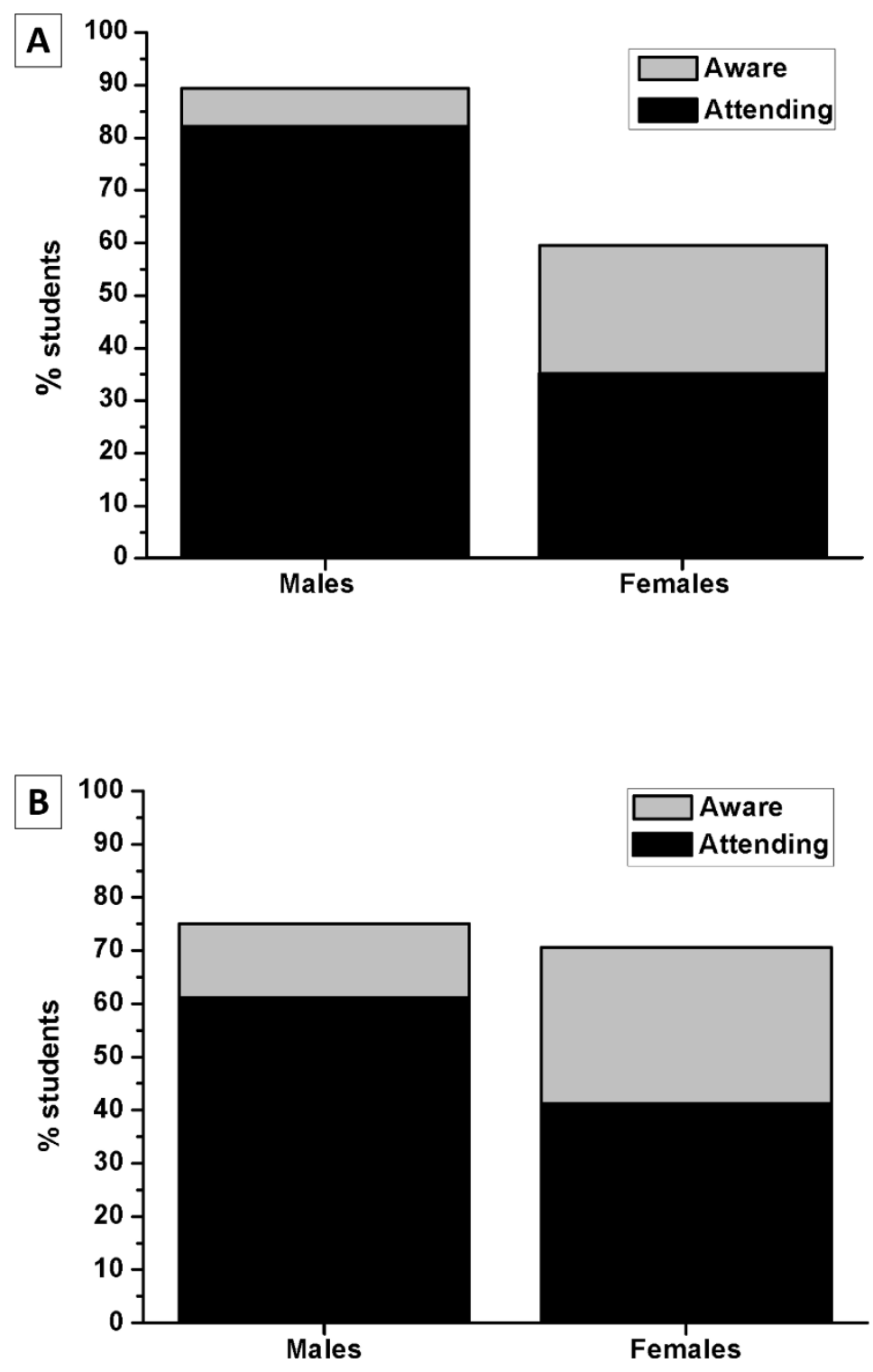

Figure 4 An overview of pupils' engagement with STEM extracurricular activities in the high school (A) and college (B) they are currently enrolled at. The graphs show the percentage of pupils aware that their institution offers extracurricular activities in science and maths, and the percentage of pupils taking part in such activities. For each gender, the percentage of "attending" pupils is calculated in relation to the total number of pupils rather than to the number of "aware" pupils.

opposed to $89 \%$ of boys) were aware that their school offered STEM extracurricular activities. Our data highlighted an even more unsettling imbalance in ECA attendance, with only $35 \%$ of females (as opposed to $82 \%$ of males) reporting attendance at STEM extracurricular activities. Interestingly, while there were only minor gender differences ( $75 \%$ of males and $71 \%$ of females) in pupils' awareness of the availability of STEM extracurricular activities in the year 12 cohort (Figure 4B), there was again a significant gap in attendance $(61 \%$ of males and $41 \%$ of females).

We then sought to investigate whether there is a correlation between pupils' attendance to STEM extracurricular activities and their intentions to pursue a career in a related field. As shown in Figure 3B, year 11 pupils who attend STEM-related extracurricular activities are twice more likely to consider pursuing a career in STEM than their peers who did not attend any. Similarly, $94 \%$ of college-age 


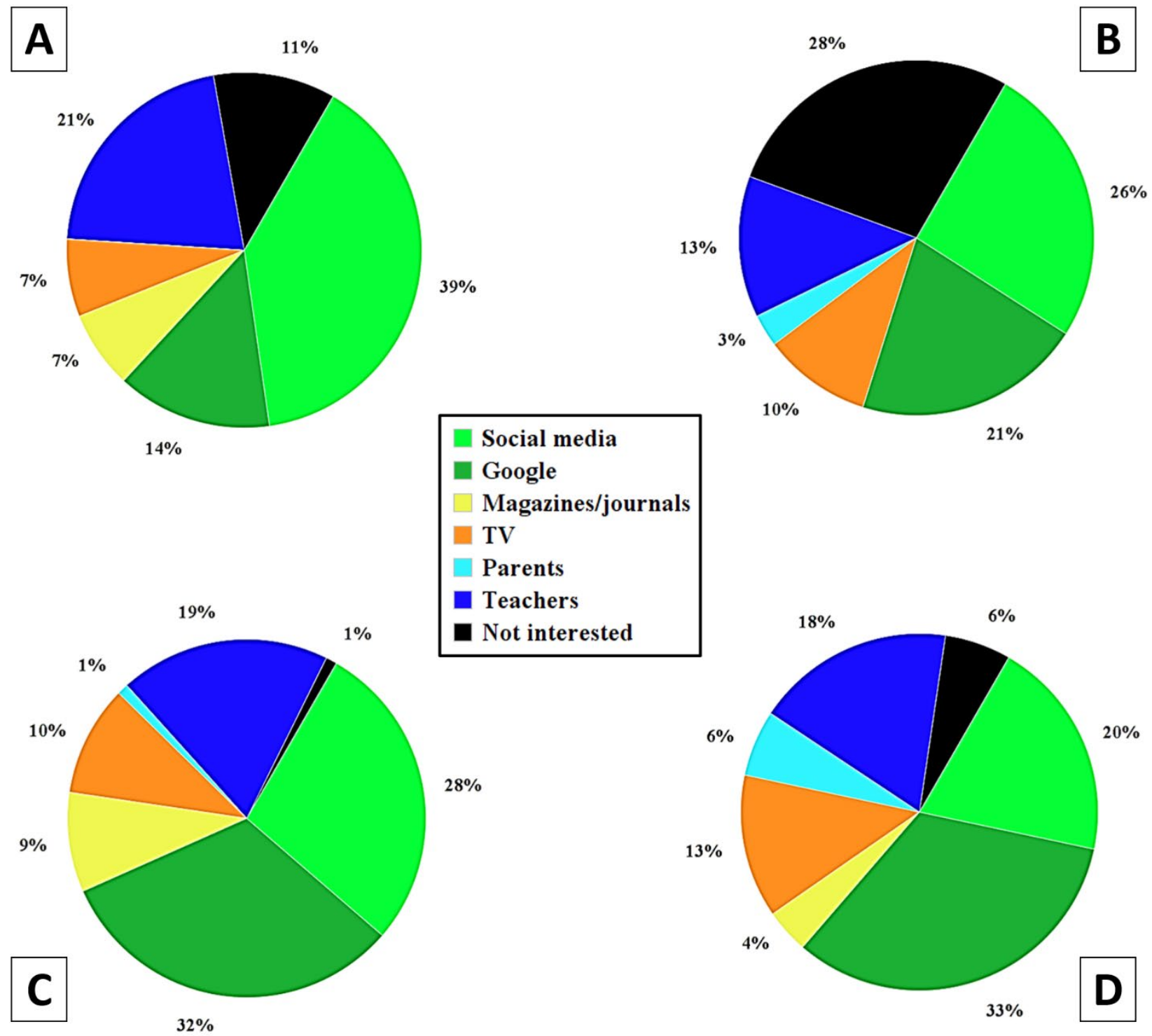

Figure 5 Pupils' preferred sources of science news for year 11 males $(A)$, year 11 females (B), year 12 males (C), year 12 females (D).

pupils who participate in STEM extracurricular activities expressed the intention of pursuing a STEM career, as opposed to only $67 \%$ of the pupils who did not participate in ECA.

To gain further insight into pupils' engagement with the broader (i.e. not strictly classroom based) scientific context, we investigated their choice of means when accessing sciencerelated news. Not surprisingly, our results (Figure 5) indicate that the internet (Google and social media) is by far the preferred means pupils use to gain scientific information, taking up approximately $50 \%$ of the total preferences across both genders and age groups. A considerably smaller proportion of the participants indicated teachers ( $20 \%)$ and parents $(<10 \%)$ as their source of science news. It is a reason of concern that, in both year groups, girls were substantially more likely than boys to declare that they were "not interested" in obtaining science news. 
An evaluation of gender bias and pupils' attitude towards STEM disciplines

\begin{tabular}{|l|l|}
\hline A & "I would like to go on more trips to see more real life applications of science" \\
\cline { 2 - 3 } & "Get scientists to come and talk about their research" \\
\cline { 2 - 3 } & "Use a variety of different activities instead of listening to a teacher for the whole lesson" \\
\cline { 2 - 3 } & "Do more experiments instead of watching videos" \\
\cline { 2 - 3 } & "More activities for kinaesthetic learners" \\
\cline { 2 - 3 } & "Learn more about space and do more interesting practicals" \\
\hline on" workbooks more often and make sure that a topic is fully understood before moving & "Hear about science that is happening in real life from scientists" \\
\hline "Having better equipment, using better microscopes, studying living microorganisms" \\
\hline "Talking about the applications of science and the paths it can take you in life" \\
\hline "More complex practicals using more specialised equipment" \\
\hline $\begin{array}{l}\text { "Study more practical aspects than copying into books, do more interactive activities, } \\
\text { videos, teamwork, etc" }\end{array}$ \\
\hline $\begin{array}{l}\text { "There is not really a way, we do lots of practicals which are very interesting, but there is } \\
\text { so much content to get through" }\end{array}$ \\
\hline $\begin{array}{l}\text { "Doing more activities where students are involved in lessons, more quizzes and team } \\
\text { activities" }\end{array}$ \\
\hline
\end{tabular}

Table 2 Representative answers of year $11(\mathrm{~A})$ and year $12(\mathrm{~B})$ pupils to the question "How could we make science lessons more interesting and appealing to you?"

\section{Discussion and conclusions}

The results of our study not only corroborate previously observed trends, but also provide novel insight into the social and psychological dynamics that underpin them.

As discussed in the introduction, it is widely acknowledged that the STEM field is a heavily polarised one, with gender representation varying widely between subjects. Our results indicate that this phenomenon is already prevalent in Key Stage 4, with girls expressing the majority of preferences for biology, and a limited interest in physics, mathematics, and (albeit with a less pronounced gap) chemistry. These findings corroborate Boaler's observation of A-level enrolments showing a "low participation of young women in all of the UK countries in mathematics and physics, with chemistry offering more equal participation, and biology greater participation from young women" (Boaler, et al., 2011). Surprisingly, among the participants in our study, girls studying science for their A-levels expressed a higher share of preferences for mathematics than their male peers (Figure
1B). This finding, combined with the lack of gender imbalance in year 12 pupils' intentions to enrol in a university course (Figure 2B) and to pursue a career in a STEM field (Figure $3 A$ ) seems to indicate that the transition from level 2 to level 3 might be a more critical "leaky junction" than the transition from level 3 to level 4, making the former an appealing target for interventions aimed at mending the pipeline at an early stage. Sapna Cheryan and colleagues investigated the factors underpinning the differential gender imbalance in the STEM subjects, and proposed a three-factors model to explain it (Cheryan, et al., 2017). In Cheryan's model, "Insufficient early experience" figures as a core attrition factor that, when combined with "Masculine culture of the fields" and the previously discussed "Gender gaps in selfefficacy", contribute to the observed "Lower representation of women in computer science, engineering, \& physics vs. biology, chemistry, \& mathematics".

In the study that was discussed earlier on, Codiroli reported that "parental education, but 
not social class or financial resources, influence students' choices. Students studying STEM A-levels are more likely to have fathers with a degree" (Codiroli, 2017). Pupils' responses to our survey seem to confirm this observation, as both year 11 and year 12 students were keener to pursue further academic studies if at least one of their parents or carers was in possession of a higher education degree. It is important to underline that, as for the results discussed in the previous paragraph, a wider gap could be observed amongst year 11 students than year 12 students, further supporting the hypothesis that the transition from Key Stage 4 to Key Stage 5 is a critical moment in young people's engagement with STEM, arguably even more so than the transition to higher education. Indeed, this should probably not come as a surprise, as the year 12 cohort was composed of students who had already chosen to pursue their A levels in a STEM subject, and were therefore more committed to, or at least interested in, pursuing a career in the field.

Attendance at extracurricular activities has been proven to have a direct impact on secondary students' decisions to pursue a STEM career in higher education (Bottia, et al., 2015; Kesidou \& Koppal, 2004). Although we did not attempt to establish a causative link, our results seem to corroborate Bottia's observations: pupils engaged in STEM extracurricular activities were considerably more likely to express the intention to pursue a career in a STEM field. The observed gender gap in the attendance at extracurricular activities is a clear indicator of a lack of engagement of female students with STEM subjects. It could reasonably be argued that either low attendance at ECA results in reduced engagement with STEM subjects, or vice versa; more realistically, the two phenomena can be seen as both cause and consequence of each other, acting in a selfpropagating disengagement cycle. In a recent longitudinal cohort study involving high school and undergraduate students, extracurricular experiences were found to be "the most significant factors that initially ignited their interest in STEM", supporting the hypothesis of a direct causative link between ECA and academic engagement in STEM (VanMeterAdams, et al., 2014).
Albeit anecdotal in nature, pupils' responses to the open questions in our survey (Table 2) support the possibility that "out of class" activities might have a higher impact on their engagement with STEM than traditional teaching and learning of the science curriculum. The consensus transpiring from the open answers is that students advocate a more enquiry-based approach to science teaching, are eager to learn more about the wider context in which science takes place and curious about the "real life" rationale (and practical applications) of the scientific notions they learn in the classroom. These findings mirror Boaler's remark that "many researchers have noted the increased engagement of girls in curricula in which they can find connections between the presented materials and issues in their lives and in society more generally" (Boaler et al., 2011). In that regard, many participants in our study expressed their wish to take part in more activities involving visiting scientists in addition to the lessons they undertake with their science teachers, which again resonates with Boaler's reflections in that "It is particularly important that girls perceive science, including physics, as 'something that people do, influenced by historical, political, cultural and personal factors, not just a body of knowledge'". Towards the endeavour of contextualising scientific notions and combating the "ivory tower scientists" stereotype, it is fundamental that school-age students be exposed to appropriate positive role models in order to stimulate their curiosity and foster their engagement with STEM disciplines. Popular culture has an enormous impact on the public perception of scientists and science itself, and the understanding of how they are portrayed in media such as TV and cinema is fundamental to gain "new insights to extend existing conceptual theoretical frameworks of science or STEM identity and advance understanding of STEM identity formation for adolescent girls" (Steinke \& Paniagua Tavarez, 2017).

Our results reinforce the idea that extracurricular and outreach activities can be powerful tools to foster an early interest in STEM subjects in young learners and fight the inception of stereotyped and gender-biased views of scientists and their social role. The 
last decade has seen the affirmation in the UK of several initiatives such as the "Principia Space Diary" and "STEMettes" aimed at providing school-age pupils with powerful and relatable role models (CurvedHouseKids, 2017; Stemettes, 2018). The present study corroborates the notion that not only government and policymakers, but also universities, research institutes, and private research \& development companies have a social responsibility to combat the STEM gender gap and reach out within the local communities to provide positive role models to young learners (Kesidou \& Koppal, 2004). Moreover, the provision of tailored outreach activities should be seen as a long-sighted investment towards an early engagement of school-age pupils with STEM subjects, which would undoubtedly have a positive knock-on effect on recruitment into Higher Education Institutions and development of the expertise necessary to reduce the STEM skills shortage.

\section{Disclosure statement}

The authors declare no conflict of interest.

\section{References}

Analysis of the representation of women across the hospital and community health services workforce. (2018). National Health Service. Retrieved from https://digital.nhs.uk/data-andinformation/find-data-andpublications/supplementary-information/2018supplementary-information-files/analysis-ofthe-representation-of-women-across-thehospital-and-community-health-servicesworkforce

AQA science curriculum. Assessment and Qualifications Alliance. (2018). Retrieved from https://www.aqa.org.uk/subjects/science

Athena SWAN Charter. Equality Challenge Unit. (2018). Retrieved from https://www.ecu.ac.uk/equalitycharters/athena-swan/

Blackburn, H. (2017). The Status of Women in STEM in Higher Education: A Review of the Literature 2007-2017. Science and
Technology Libraries, 36(3), pp. 235-273. DOI: 10.1080/0194262X.2017.1371658

Boaler, J. (2002). Experiencing school mathematics: traditional and reform approaches to teaching and their impact on student learning. Routledge

Boaler, J., Altendorff, L., \& Kent, G. (2011). Mathematics and science inequalities in the United Kingdom: when elitism, sexism and culture collide, Oxford Review of Education, $37: 4,457-484$.

Botcherby, S., \& Buckner, L. (2012). Women in Science, Technology, Engineering and Mathematics: from Classroom to Boardroom. UK Statistics, London

Bottia, M.C., Stearns, E., Mickelson, R.A., Moller, S., \& Parker, A.D. (2015). The Relationships among High School STEM Learning Experiences and Students' Intent to Declare and Declaration of a STEM Major in College. Teachers College Record, 117(3)

Campbell, T. (2015). Stereotyped at Seven? Biases in Teacher Judgement of Pupils' Ability and Attainment. Journal Of Social Policy, 44(3), pp. 517-547.

Ceci, S.J., Williams, W.M., Ginther, D.K., \& Kahn, S. (2014). Women in academic science: A changing landscape. Psychological Science in the Public Interest, Supplement, 15(3), 75-141. DOI: $10.1177 / 1529100614541236$

Cheryan, S., Ziegler, S. A., Jiang, L., \& Montoya, A. K. (2017). Why Are Some STEM Fields More Gender Balanced Than Others? Psychological Bulletin, 143(1), pp. 1-35.

Codiroli, N. (2017). Who studies STEM subjects at $A$ level and degree in England? An investigation into the intersections between students' family background, gender and ethnicity in determining choice. British Educational Research Journal, 43(3), pp. 528553. DOI: 10.1002/berj.3270

Curved House Kids. (2017). Inspired by Space: Engaging Girls in STEM - Principia Space Diary. Retrieved from 
An evaluation of gender bias and pupils' attitude towards STEM disciplines

https://principiaspacediary.org/inspired-byspace-engaging-girls-in-stem/

Delivering STEM (science, technology, engineering and mathematics) skills for the economy. (2018). National Audit Office.

Dweck, C.S. (1986). Motivational Processes Affecting Learning. American Psychologist, 41(10), pp. 1040-1048. DOI10.1037/0003066X.41.10.1040

Dweck, C.S., Davidson, W., Nelson, S., \& Enna, B. (1978). Sex differences in learned helplessness: II. The contingencies of evaluative feedback in the classroom and III. An experimental analysis. Developmental Psychology, 14(3), pp. 268-276. DOI: 10.1037/0012-1649.14.3.268

Fact Sheet No. 43: Women in Science. (2017). UNESCO Institute for Statistics

Gumpertz, M., Durodoye, R., Griffith, E., \& Wilson, A. (2017). Retention and promotion of women and underrepresented minority faculty in science and engineering at four large land grant institutions. PLOS ONE, 12(11), p e0187285.

Higher education student enrolments and qualifications obtained at higher education providers in the United Kingdom 2015/16. Higher Education Statistics Agency (2018). Retrieved from

https://www.hesa.ac.uk/news/12-01-

2017/sfr242-student-enrolments-andqualifications

Immigration Rules. (2016, last updated on 6/4/2018). Retrieved from https://www.gov.uk/guidance/immigrationrules/immigration-rules-appendix-k-shortageoccupation-list

Immigration: Keeping the UK at the heart of global science and engineering. (2016). CaSE, Campaign for Science and Engineering

Industrial Strategy: Building a Britain fit for the future. (2017). UK Department for Business, Energy \& Industrial Strategy.
Investing in biotechnology management: Venture Capital and Hiring Insights on Gender. (2015). Liftstream.

Kahn, S., \& Ginther, D. (2017). Women and STEM. National Bureau of Economic Research Working Paper Series, No. 23525

Kesidou, S., \& Koppal, M. (2004). Supporting Goals-Based Learning with STEM Outreach. Journal of STEM Education: Innovations \& Research, 5(3/4), pp. 5-16.

LaCosse, J., Sekaquaptewa, D., \& Bennett, J. (2016). STEM Stereotypic Attribution Bias Among Women in an Unwelcoming Science Setting. Psychology Of Women Quarterly, 40(3), pp. 378-397.

Lubienski, S.T., Miller, E.K., \& Saclarides, E.S. (2017). Sex Differences in Doctoral Student Publication Rates. Educational Researcher, 47(1), pp. 76-81.

Mujtaba, T., \& Reiss, M.J. (2012). Factors affecting whether Students in England Choose to Study Physics once the subject is Optional. London: Institute of Education.

Munir, F., Mason, C., McDermott, H., Morris, J., Bagilhole, B., \& Nevill, M. (2013). Advancing women's careers in science, technology, engineering, mathematics and medicine: Evaluating the effectiveness and impact of the Athena SWAN charter. London: Equality Challenge Unit

Nelson, L.J., \& Cooper, J. (1997). Gender Differences in Children's Reactions to Success and Failure With Computers, Computers in Human Behavior, 13(2), 247267.

Qian, G., \& Alvermann, D. (1995). Role of epistemological beliefs and learned helplessness in secondary school students' learning science concepts from text. Journal of Educational Psychology, 87(2), pp. 282292. DOI: $10.1037 / 0022-0663.87 .2 .282$

Ryckman, D.B., \& Peckham, P.D. (1987). Gender Differences in Attributions for Success and Failure. The Journal of Early 
An evaluation of gender bias and pupils' attitude towards STEM disciplines

Adolescence, 7(1), pp. 47-63. DOI: Stemettes. (2018). Retrieved from $10.1177 / 0272431687071006$

http://stemettes.org/

Sadler, P.M., Sonnert, G., Hazari, Z., \& Tai, R. (2012). Stability and Volatility of STEM Career Interest in High School: A Gender Study. Science Education, 96(3), pp. 411-427.

Smith, E. (2011). Women into science and engineering? Gendered participation in higher education STEM subjects. British Educational Research Journal, 37(6), pp. 993-1014. DOI: $10.1080 / 01411926.2010 .515019$

Steinke, J., \& Paniagua Tavarez, P.M. (2017). Cultural Representations of Gender and STEM: Portrayals of Female STEM Characters in Popular Films 2002-2014. International Journal of Gender, Science \& Technology, 9(3), p 244.

The Supply of and Demand for High-Level STEM Skills. (2013). UK Commission for Employment And Skills.

VanMeter-Adams, A., Frankenfeld, C.L., Bases, J., Espina, V., \& Liotta, L.A. (2014). Students Who Demonstrate Strong Talent and Interest in STEM Are Initially Attracted to STEM through Extracurricular Experiences. CBE - Life Sciences Education, 13(4), pp. 687-697.

When women thrive, businesses thrive. (2016). Mercer.

Women in STEM workforce. (2017). Retrieved from

https://www.wisecampaign.org.uk/resources/2 $\underline{017 / 10 / \text { women-in-stem-workforce-2017 }}$ 